CIRJE-F-850

\title{
Estimating a Search and Matching Model of the Aggregate Labor Market in Japan
}

\author{
Ching-Yang Lin \\ International University of Japan \\ Hiroaki Miyamoto \\ International University of Japan
}

April 2012

CIRJE Discussion Papers can be downloaded without charge from:

http://www.cirje.e.u-tokyo.ac.jp/research/03research02dp.html

Discussion Papers are a series of manuscripts in their draft form. They are not intended for circulation or distribution except as indicated by the author. For that reason Discussion Papers may not be reproduced or distributed without the written consent of the author. 


\title{
Estimating a Search and Matching Model of the Aggregate Labor Market in Japan
}

\author{
Ching-Yang Lin \\ International University of Japan International University of Japan \\ Hiroaki Miyamoto*
}

First Draft: March 3, 2012

This version: April 18, 2012

\begin{abstract}
This paper studies how well a search and matching model can describe aggregate Japanese labor market dynamics in a full information setting. We develop a discretetime search and matching model with productivity and separation shocks and use it as a data-generating process for our empirical analysis. Using Bayesian methods, we estimate the model for data on unemployment and vacancy postings in Japan. We find that the model is successful in matching the volatility in unemployment and vacancies while it does not match the volatility of output and wages. We also find that both productivity and separation shocks contribute to movements in unemployment and vacancies, but productivity shocks more so.
\end{abstract}

JEL Classification: C11; C51; E24; J64

Keywords: Search and matching model; Unemployment; Bayesian Estimation; Japanese labor market

\section{Introduction}

The search and matching model has been often used for studying aggregate labor markets. However, the model has recently criticized for its inability to account for the cyclical

\footnotetext{
${ }^{*}$ Corresponding author, International University of Japan, E-mail: hmiyamot@iuj.ac.jp. This paper was written during my stay in the Center for International Research on the Japanese Economy (CIRJE) at the University of Tokyo. I am very grateful for their hospitality. Part of this research is supported by the Grants-in-Aid for Young Scientists of the Japan Society for the Promotion of Science (Kakenhi No. 23730197 and No. 24730179).
} 
properties of the U.S. labor market. Shimer (2005) demonstrates that the model cannot generate the observed unemployment and vacancy fluctuations in response to productivity shocks of reasonable size. This failure of the model has come to be known as the "Shimer puzzle". ${ }^{1}$ Recently, a number of papers study whether the Shimer puzzle holds for the Japanese labor market (Esteban-Pretel et al., 2011; Miyamoto, 2011; Tawara, 2011). ${ }^{2}$ In order to examine whether the model is able to capture the data, these studies use the calibration method and concentrate on the model's ability to replicate a few key statistics. One issue with such an approach is that information on some parameters in the model is difficult to pin down. ${ }^{3}$ Furthermore, it is hard to study the quantitative implications of the entire model.

The purpose of the paper is to study how well the search and matching model can describe aggregate Japanese labor market dynamics in a full information setting. To do so, we treat the model as a data-generating process for aggregate labor market variables. We treat the observed unemployment and vacancy postings as arising from the job-worker searching process in the search and matching model. We focus on the parameter estimates that are consistent with the cyclical labor market dynamics in the full data set, and the contribution of various driving forces to labor market fluctuations.

We develop a simple discrete-time search and matching model with a standard productivity shock and a separation shock. Recent empirical studies demonstrate that both unemployment inflow and outflow rates significantly contribute the unemployment dynamics in Japan (See for example, Lin and Miyamoto, 2012). ${ }^{4}$ In order to capture the importance of unemployment inflow channel in generating unemployment fluctuations, we incorporate a persistent shock to the separation rate of workers into unemployment.

We estimate the model using Bayesian methods for data on unemployment and vacancies in Japan. While model parameters are chosen to match selected data moments in calibration methods, they are selected by taking into account all moments of the data in our structural estimation. The structural estimation of the full model allows us to examine the ability of the model as a plausible description of labor market dynamics. The model

\footnotetext{
${ }^{1}$ In the literature, many solutions have been proposed to solve this problem. See Hornstein, Krusell, and Violante (2005) and Nagypál and Mortensen (2007) for surveys.

${ }^{2}$ While the methodology to answer the question is different among these studies, all papers reach the same conclusion that the Shimer puzzle holds for the Japanese economy.

${ }^{3}$ As Lubik (2009) mentioned, calibrating the search and matching model tends to be problematic since some of the model parameters, such as the flow value of unemployment and the worker's bargaining power, are difficult to pin down.

${ }^{4}$ Lin and Miyamoto (2012) examine the relative importance of inflow and outflow rates for fluctuations in unemployment, and find approximately a 50:50 inflow/outflow split to unemployment variation in Japan.
} 
replicates the high volatilities of unemployment and vacancies and a negative relationship between them (the Beveridge curve) in the data. In order to match the data, the model estimates requires a high replacement ratio and a low worker's bargaining power. These parameter estimates are consistent with what Hagedorn and Manovskii (2008) suggest in their calibration. Another important finding is that both productivity and separation shocks contribute to movements in unemployment and vacancies, but productivity shocks more so. We find that productivity shocks explain 72 percent of the volatility in unemployment and 99 percent in vacancies.

We find that the search and matching model is successful in matching unemployment and vacancy dynamics. However, the model does not match the volatility of unobserved variables, output and wages. First, the model predicts higher volatility in output what we observe in the data. This implies that a search and matching model fails to generate the observed unemployment and vacancies fluctuations in response to productivity shocks of reasonable size even under parameter values that are estimated to match the full data set. Second, the model predicts higher volatility in wages than data. This fact suggests the necessity of a source of wage rigidity to make the model match the data. We demonstrate that the incorporation of wage rigidity improves the model's ability to match the volatility of labor market variables. However, the model still fails to account for the volatility in output.

This study is related to the recent literature on the quantitative implications of the search and matching model. A number of papers study the ability of the search and matching model to account for the cyclical properties of the Japanese labor market (EstebanPretel et al., 2011; Miyamoto, 2011; Tawara, 2011). While they use the calibration methods and concentrate on the model's ability to replicate a few key statistics, we rather study the quantitative implications of the entire search and matching model by using Bayesian estimation. This paper reaches the conclusion that the Shimer puzzle holds for the Japanese economy as previous studies obtained. With our best knowledge, this is the first structural empirical study of the search and matching model for Japan.

This paper is closely related to Lubik $(2009,2011)$. He estimates a search and matching model using Bayesian methods for the U.S. data and the Hong-Kong data. He demonstrates that basically a search and matching model is successful in describing the US and HongKong labor markets well. However, Lubik (2009) shows that the success of the model relies on atypical shock process that may not have economic justification. By using the Japanese data, we show that the search and matching model succeeds to explain the dynamics of unemployment and vacancies well. However, we show that the model still 
fails to generate the observed volatilities in labor market variables relative to output. This finding complements the results of Lubik (2009, 2011).

The remainder of the paper is organized as follows. Section 2 develops a simple discretetime search and matching model with productivity and separation shocks. We use this model as a data-generating process for our empirical analysis. In Section 3, we discuss the data and priors used for our estimation. We then present the estimation results. Section 4 discusses the model's ability to fit the data and sources of labor market fluctuations. In Section 5, we conduct a robustness check and then discuss the role of wage rigidity. Section 6 concludes.

\section{The model}

We develop a discrete time search and matching model that we use as a data-generating process for the empirical analysis. The basic structure of the model follows Pissarides (2000). The point of departure in the study is that we incorporate a persistent shock to a separation rate in order to capture the importance of unemployment inflow channel in generating unemployment fluctuations.

The environment An economy consists of a continuum of identical workers normalized to one and a large number of identical risk-natural firms. A worker can be either employed or unemployed. If a worker is unemployed, he gets a flow utility from non-market activity and searched for a job. If he is employed, he produces output and earns wages. Firms recruit workers by posting vacancies. Firms maximize their intertemporal profit functions by choosing the number of vacancies to be posted. Each firm produces a flow of output, paying workers wages and incurring hiring costs. Workers are separated from jobs at a stochastic exogenous rate.

The labor market The labor market is subject to frictions and firms and workers cannot meet instantaneously but must go through a time-consuming search process. The number of successful job matches is determined by the Cobb-Douglas matching function,

$$
m\left(u_{t}, v_{t}\right)=m u_{t}^{\alpha} v_{t}^{1-\alpha}
$$

where $u_{t}$ is the number of unemployed workers, $v_{t}$ is the number of vacancies, $m$ represents match efficiency and $0<\alpha<1$ is the elasticity of the matching function with respect to unemployment. Define $\theta_{t} \equiv v_{t} / u_{t}$, as labor market tightness. The probability of a firm 
with a vacancy is matched with a worker is $m\left(u_{t}, v_{t}\right) / v_{t}=m \theta_{t}^{-\alpha} \equiv q\left(\theta_{t}\right)$. Similarly, the probability that an unemployed worker is matched is $m\left(u_{t}, v_{t}\right) / v_{t}=m \theta_{t}^{1-\alpha}=\theta_{t} q\left(\theta_{t}\right)$. The number of employed workers is defined as

$$
n_{t}=1-u_{t}
$$

Matches are destroyed at an exogenous rate $s_{t}$ which takes place at the end of period $t$. We allow for time variation in the separation rate. Specifically, we assume that $\log s_{t}$ follows a first-order autoregressive process of the form

$$
\log s_{t}=\left(1-\rho_{s}\right) \log s+\rho_{s} \log s_{t-1}+\varepsilon_{s, t},
$$

where $0<\rho_{s}<1,0<s<1$ and $\varepsilon_{s, t} \sim N\left(0, \sigma_{s}^{2}\right)$.

We assume that it takes one period for new matches to be productive and that both old and new matches faces the same separation rate. The evolution of employed workers is given by

$$
n_{t}=\left(1-s_{t}\right)\left[n_{t-1}+m u_{t-1}^{\alpha} v_{t-1}^{1-\alpha}\right] .
$$

Thus, the number of employed workers at time $t$ is given by the number of employed worker at time $t-1$ plus new matches formed in period $t$ that were not destroyed.

Firms' optimization Production takes place when a firm is matched with workers. Output $y_{t}$ of a typical firm is linear in employment $n_{t}$ :

$$
y_{t}=A_{t} n_{t}
$$

where $A_{t}$ is an aggregate productivity and follows a first-order autoregressive process of the form

$$
\log A_{t}=\left(1-\rho_{A}\right) \log A+\rho_{A} \log A_{t}+\varepsilon_{A, t},
$$

where $0<\rho_{A}<1$ and $\varepsilon_{A, t} \sim N\left(0, \sigma_{A}^{2}\right)$.

In order to hire workers, firms have to post vacancies. The cost of posting vacancies is $\kappa v_{t}^{\phi} / \phi$ where $\kappa>0$ and $\phi>0 .{ }^{5}$ A firm pays workers real wage $w_{t}$, which is derived below. The firm chooses the optimal number of vacancies $v_{t}$ to be posted and its employment level $n_{t}$ by maximizing the following intertemporal profit function

$$
\mathbb{E}_{t} \sum_{t=0}^{\infty} \beta^{t}\left[A_{t} n_{t}-w_{t} n_{t}-\frac{\kappa}{\phi} v_{t}^{\phi}\right]
$$

\footnotetext{
${ }^{5}$ In the standard search and matching model, the cost of positing vacancies is assumed to be linear. As Rotemberg (2008) argues, it need not be the case when we consider large firms. Therefore, in this paper, we consider a more general recruiting cost function. Note that the case of $\phi=1$ corresponds to the vacancy cost function in the standard model.
} 
subject to the equation of employment evolution (2). The first-order conditions are

$$
\begin{aligned}
\mu_{t} & =A_{t}-w_{t}+\beta \mathbb{E}_{t}\left[\mu_{t+1}\left(1-s_{t+1}\right)\right], \\
\frac{\kappa v_{t}^{\phi-1}}{q\left(\theta_{t}\right)} & =\beta \mathbb{E}_{t}\left[\mu_{t+1}\left(1-s_{t+1}\right)\right],
\end{aligned}
$$

where $\mu_{t}$ is the Lagrangean multiplier on constraint (2).

Making use of these two first-order conditions, we can obtain the job creation condition

$$
\frac{\kappa v_{t}^{\phi-1}}{q\left(\theta_{t}\right)}=\beta \mathbb{E}_{t}\left[\left(A_{t+1}-w_{t+1}+\frac{\kappa v_{t+1}^{\phi-1}}{q\left(\theta_{t+1}\right)}\right)\left(1-s_{t+1}\right)\right] .
$$

The job creation condition states that expected cost of positing a vacancy, the left-hand side of (3), is equal to the firm's share of the expected new surplus from a new job match, the right-hand side of $(3)$.

Wage determination Wage are determined by Nash bargaining between a firm and a worker, where the worker has bargaining power $\eta \in(0,1)$. The surplus sharing implies

$$
(1-\eta)\left(W_{t}-U_{t}\right)=\eta J_{t}
$$

where $W_{t}$ is the value of an employed worker, $U_{t}$ is the value of an unemployed worker, and $J_{t}$ is the value of the marginal value of the worker to the firm.

The value of an employed worker is characterized by the following Bellman equation:

$$
W_{t}=w_{t}+\beta \mathbb{E}_{t}\left[\left(1-s_{t+1}\right) W_{t+1}+s_{t+1} U_{t+1}\right]
$$

The value of $W_{t}$ is determined by several factors. In the current period, the worker receives wage $w_{t}$. In the next period, while the worker retains his job with probability $1-s_{t+1}$, he loses the job and becomes unemployed with probability $s_{t+1}$,.

The value of an unemployed worker is

$$
U_{t}=b+\beta \mathbb{E}_{t}\left[\theta_{t} q\left(\theta_{t}\right)\left(1-s_{t+1}\right) W_{t+1}+\left(1-\theta_{t} q\left(\theta_{t}\right)\left(1-s_{t+1}\right)\right) U_{t+1}\right]
$$

An unemployed worker receives unemployment benefits $b$ and transitions into employment with probability $\theta_{t} q\left(\theta_{t}\right)\left(1-s_{t+1}\right)$.

The value of the marginal worker to the firm $J_{t}$ is equivalent to the Lagrangean multiplier on employment constraint $\mu_{t}$, which is the shadow value of a filled job. Thus, the value of a filled job is

$$
J_{t}=A_{t}-w_{t}+\beta \mathbb{E}_{t}\left[J_{t+1}\left(1-s_{t+1}\right)\right]
$$


By using the wage sharing rule (4), value functions (5), (6), (7), and the first-order conditions, we obtain the following wage equation

$$
w_{t}=\eta A_{t}+(1-\eta) b+\eta \theta_{t} \kappa v_{t}^{\phi-1}
$$

By substituting (8) into (3), the job creation condition (3) can be rewritten as

$$
\frac{\kappa v_{t}^{\phi-1}}{q\left(\theta_{t}\right)}=\beta \mathbb{E}_{t}\left(1-s_{t+1}\right)\left[(1-\eta)\left(A_{t+1}-b\right)-\eta \theta_{t+1} \kappa v_{t+1}^{\phi-1}+\frac{\kappa v_{t+1}^{\phi-1}}{q\left(\theta_{t+1}\right)}\right]
$$

The dynamics of the model are given by the four equations (1), (2), and (9) the definition of the labor market tightness that solves for five unknowns $n_{t}, u_{t}, v_{t}$, and $\theta_{t}$.

\section{Estimation}

The model is estimated by using Bayesian methods. First, we log-linearize the non-linear model around a deterministic steady state. ${ }^{6}$ We then solve the model and apply the Kalman filter to evaluate the likelihood function of the observable variables. The likelihood function and the prior distribution of the parameters in the model are combined to obtain the posterior distribution. The posterior kernel is simulated numerically by employing the random-walk Metropolis-Hastings algorithm. ${ }^{7}$ We first discuss the data and the priors used in the estimation and then report the results.

\subsection{Data and Priors}

The model is estimated by using two key labor market variables: the unemployment rate and the vacancy rate. The sample covers 1980Q1-2009Q4. We obtain the unemployment rate from the Labour Force Survey (LFS) conducted by the Statistics Bureau and the Director-General for Policy Planning. The vacancy rate is obtained from the monthly Report on Employment Service (Shokugyo Antei Gyomu Tokei) conducted by the Ministry of Health, Labour and Welfare. We define job vacancies as the difference between the number of active job openings (yuko-kyuujin-suu) and the number of job placements (shushoku-ken-suu). Then, the vacancy rate is computed as $100 \times$ job vacancies/(job va-

\footnotetext{
${ }^{6}$ The log-linearized verison of the model is presented in Appendix.

${ }^{7}$ Details on the estimation procedure can be found in An and Schorfheide (2007) and Lubik (2009).
} 
cancies+employment). ${ }^{8}$ All data are seasonally adjusted and de-trended using HodrickPrescott filter with smoothing parameter 1,600.

The use of two data series requires the inclusion of at least two independent sources of variation. We estimate the model by using two shocks: a productivity shock $A_{t}$ and a separation shock $s_{t}$. We normalize the mean of the productivity process $A_{t}$ to one and that of the separation shock is a structural parameter to be estimated.

The model contains 12 structural parameters, excluding the shock parameters. We choose priors for the Bayesian estimation based on the typical values in calibration studies. We set the discount rate $\beta=0.99$ because the annual real interesting rate has been around 4\%. The remaining parameters are estimated. We use Beta distributions for parameters that take sensible values between zero and one, Gamma distributions for realvalued parameters, and the inverse Gamma distributions for the shock variances.

Kano and Ohta (2002) estimate the matching function in Japanese labor market by using aggregate data, and obtain the elasticity of the matching function $\alpha$ of about 0.6. We set $\alpha$ at a mean of 0.6 with a standard deviation of 0.15 . The prior of the matching constant $m$ is chosen to be consistent with the observed job-finding rate of 0.142 per month (Miyamoto, 2011). This leads to a prior mean of 0.15 . The prior mean of the separation rate $s$ is set to 0.012 , as estimated by Miyamoto (2011).

We now choose priors for the unemployment benefit $b$ and the worker's bargaining power $\eta .{ }^{9}$ These two parameters have been the subject of some discussion in the literature. Martin (1998) computes the average replacement rates, the ratio of unemployment benefits to average wages, in the OECD countries and reports that the replacement rate in Japan is about 0.6. We set $b$ at a mean of 0.6 with a wide coverage region. Regarding the worker's bargaining power, since we are interested in how much information on $\eta$ is in the data, we choose a uniform prior over the unit interval.

Regarding parameters in the vacancy cost function, the prior mean of the vacancy

\footnotetext{
${ }^{8}$ It is important to note that job vacancies are not measured on the same basis as economy-wide unemployment. Although the data on vacancies are not perfect, this study uses this data source because it is the only available data that covers long periods consistently.

${ }^{9}$ Much of the debate on the viability of the search and matching model as a description of the labor market centers around these parameter values. Shimer (2005) sets $b$ by targeting the replacement ratio of 0.4. Hagedorn and Manovskii (2008) argue that Shimer's choice of the value of the opportunity cost of employment is too low because it does not allow for the value of leisure, home production, or unemployment benefits. They calibrate the opportunity cost of employment and the worker's bargaining power to match the observed cyclical response of wages and average profit rate. Their results are $b=0.955$ and $\eta=0.052$. Mortensen and Nagypál (2007) criticize Hagedorn and Manovskii (2008) for using these parameters because these parameters yield workers a gain of $2.8 \%$ in flow utility by going from unemployment to employment.
} 
positing elasticity $\phi$ is set equal to 1 with a large standard deviation. Linear vacancy cost is the standard assumption in the literature. Then, the scale parameter is set to $\kappa=0.45$, which is obtained from the steady-state solutions of the model.

The prior mean of the autoregressive parameters is set equal to 0.5 and the prior mean of the standard errors is set equal to 0.15 for all shocks. These values are commonly used in the literature. The priors are summarized in Table 1.

Table 1: Prior distributions

\begin{tabular}{lllll}
\hline \hline Parameter & Description & Density & Mean & Std. Dev. \\
\hline$\beta$ & Discount rate & Fixed & 0.99 & - \\
$\alpha$ & Match elasticity & Beta & 0.60 & 0.15 \\
$m$ & Match efficiency & Gamma & 0.15 & 0.05 \\
$s$ & Separation rate & Beta & 0.012 & 0.002 \\
$\eta$ & Worker's bargaining power & Uniform & 0.50 & 0.25 \\
$b$ & Unemployment benefit & Beta & 0.60 & 0.2 \\
$\phi$ & Elasticity of vacancy creation & Gamma & 1.0 & 0.50 \\
$\kappa$ & Scaling factor on vacancy creation & Gamma & 0.45 & 0.10 \\
$\rho_{i}$ & AR-coefficients of shocks & Beta & 0.50 & 0.15 \\
$\sigma_{i}$ & Standard deviation of shocks & Inverse Gamma & 0.01 & 1.00 \\
\hline
\end{tabular}

\subsection{Parameter estimates}

Table 2 reports posterior means together with their 90 percent confidence intervals. Table 2 shows that most of the parameters are moved considerably from their prior means, indicating the data are informative about the values of estimated parameters.

We begin by seeing the worker's bargaining power $\eta$ and the unemployment benefit $b$. The posterior mean of the worker's bargaining power and the unemployment benefit is 0.31 and 0.87 , respectively. They are moved away considerably from the priors. This indicates that the data are informative. These parameter estimates support the argument of Hagedorn and Manoskill (2008) that a high value of an unemployed worker and the low value of the worker's bargaining power are needed to match the volatility of unemployment and vacancy. They render the wage less volatile and provide the incentives for firms post vacancies, inducing a high volatility of unemployment and vacancies.

The posterior mean of the vacancy posting elasticity $\phi=3.86$ is considerably shifted away from the prior. The estimated $\phi$ suggests that vacancy creation is more costly to the 
Table 2: Parameter estimates

\begin{tabular}{lllll}
\hline \hline \multirow{2}{*}{ Parameter } & Description & \multicolumn{2}{l}{ Prior } & \multicolumn{2}{l}{ Posterior } \\
& & Mean & Mean & 90 Percent Interval \\
\hline$\alpha$ & Match elasticity & 0.60 & 0.598 & {$[0.558,0.641]$} \\
$m$ & Match efficiency & 0.15 & 0.264 & {$[0.189,0.336]$} \\
$s$ & Separation rate & 0.012 & 0.011 & {$[0.008,0.015]$} \\
$\eta$ & Worker's bargaining power & 0.50 & 0.307 & {$[0.000,0.636]$} \\
$b$ & Unemployment benefit & 0.60 & 0.866 & {$[0.747,0.978]$} \\
$\phi$ & Elasticity of vacancy creation & 1.0 & 3.859 & {$[2.786,4.862]$} \\
$\kappa$ & Scaling factor on vacancy creation & 0.45 & 0.419 & {$[0.263,0.573]$} \\
$\rho_{A}$ & AR-coefficients of shocks & 0.50 & 0.912 & {$[0.872,0.954]$} \\
$\rho_{s}$ & AR-coefficients of shocks & 0.50 & 0.309 & {$[0.094,0.521]$} \\
$\sigma_{A}$ & Standard deviation of shocks & 0.01 & 0.026 & {$[0.005,0.048]$} \\
$\sigma_{s}$ & Standard deviation of shocks & 0.01 & 0.028 & {$[0.018,0.036]$} \\
\hline
\end{tabular}

firm because marginal vacancy posting costs are increasing in the number of vacancies. This estimate is substantially different from what most of papers assume in their calibration. In the literature, vacancy cost function is assumed to be linear. The high value of $\phi$ may be interpreted as a balancing factor that mitigates excessive vacancy creation due to the low worker's bargaining power. The estimate of the scale parameter $\kappa$ is not identified in a purely econometric sense, since the posterior distribution overlaps with the prior. This finding is consistent with Lubik $(2009,2011)$.

The posterior means of the match elasticity $\alpha$ and the separation rate $s$ are close to their prior means. The posterior mean of the match elasticity $\alpha=0.598$ is in the plausible range of 0.5-0.7 reported by Petrongolo and Pissarides (2001). The posterior mean of the separation rate is equal to 0.011 , which is in line with Japanese data.

\section{The model evaluation}

In this section, we first assess the ability of the model to capture the data. We then compute variance decompositions in order to investigate the sources of fluctuations in the labor market. We also study the effects of productivity and separation shocks on unemployment and vacancies by computing impulse response functions.

In order to see how the model fits the data, we compute various statistics from simulation of the estimated model with parameters set at their posterior means. We first 


\begin{tabular}{lll} 
Table 3: & Data and & Model Fit \\
\hline$\sigma(u)$ & Data & Model \\
\hline$\sigma(v)$ & 0.061 & 0.062 \\
$\sigma(w)$ & 0.095 & 0.085 \\
$\sigma(y)$ & 0.010 & 0.052 \\
$\rho(u, v)$ & -0.803 & -0.065 \\
\hline
\end{tabular}

assess the fit of the model by looking at the volatility of unemployment and vacancies. The model accounts for the volatility of the two variables remarkably well. The standard deviations of unemployment and vacancies are 0.061 and 0.095 , respectively. The corresponding value implied by the model are 0.062 and 0.085 , respectively. This result implies that the search and matching model is a good data-generating process for unemployment and vacancies. It seems that this argument is in contrast to Shimer (2005). However, our results require the two exogenous disturbances, i.e., productivity and separation shocks, while Shimer (2005) considers only productivity shocks in his model. Furthermore, the model requires a low worker's bargaining power and a high replacement ratio in order to match the data. Thus, the estimation result pushes the parameters toward values that Hagedorn and Manovskii (2008) suggest in their calibration. The model is also successful in capturing a high negative correlation between unemployment and vacancies.

So far we evaluate the model's ability to capture the data by looking at the observed variables, unemployment and vacancies. A more proper evaluation of the model assesses its predictions for unobserved variables. We now compute the volatility of the output and the wage from simulation of the estimated model and compare them with the data. The output series is labor productivity that is measured as real output per employed workers. The output measure is based on the National Income and Product Accounts, while employment is constructed by Statistics Bureau and Statistics Center. For the series of wages, we use the real wage indices from Monthly Labour Survey conducted by the Ministry of Health, Labour and Welfare. ${ }^{10}$ The model fails to account for the volatility in output. The relative standard deviations of unemployment and vacancies to output in the data are 4.51 and 7.04, respectively. The corresponding values implied by the model are 0.95 and 1.31, respectively. Thus, the Shimer puzzle holds even under the parameter

\footnotetext{
${ }^{10}$ This survey is for establishments with at least 30 regular employees, including part-time workers. The output and wage data are seasonally adjusted and de-trended using Hodrick-Prescott filter with smoothing parameter 1,600.
} 
values supported by the full information of the data set. ${ }^{11}$ The model also fails to capture the volatility of wages and predicts higher volatility in wages. This suggests the necessity of a source of wage rigidity to capture the wage pattern.

Next, we examine whether the model can replicate the dynamic relationship between unemployment and vacancies, i.e., the Beveridge curve. Figure 1 presents the cross correlations between these two variables. In Figure 1, the current period unemployment rate is associated with leaded and lagged values of vacancies up to four quarters. The contemporaneous correlation between unemployment and vacancies observed in data is reasonably matched by the value generated by the model. Regarding the lead-lag relationship, the data shows a tendency that vacancies leads unemployment. This pattern is captured in the data generated by the model, since correlations between current unemployment and lagged values of vacancies tend to be lager in absolute value than those between current unemployment and future values of vacancies. However, the model fails to replicate the size of the cross-correlation between unemployment and vacancies.

\begin{tabular}{ccc} 
Table 4: & Variance decompositions \\
\hline \hline & Productivity & Separation \\
\hline$u$ & 0.72 & 0.28 \\
$v$ & 0.99 & 0.01 \\
\hline
\end{tabular}

We now compute variance decomposition to study the sources of business-cycle. Specifically, we are interested in how much productivity and separation rate shocks contribute to movements in unemployment and vacancies. The results are reported in Table 4 . Both shocks play an important role, but productivity shocks contribute the volatility in unemployment and vacancies more. Productivity shocks explain 72 percent of the volatility in the unemployment rate and 99 percent in the vacancy rate. Separation shocks are relatively more important in driving unemployment than vacancies since separation shocks take the role of a residual in the employment equation (2).

Figure 2 plots impulse response functions of unemployment and vacancies to positive one-standard deviation shocks to productivity and the separation rate. They are computed at the posterior means of the structural parameters. On impact, a positive productivity shock leads to an increase in vacancies. A higher productivity level encourage firms open

\footnotetext{
${ }^{11}$ Our finding is not inconsistent with Shimer (2005). While he computes the volatility of unemployment and vacancies given a process of productivity shocks, we take a revise route by making the model fit the observed unemployment and vacancy fluctuations to examine the model's prediction on output volatility.
} 
more vacancies since it increases the expected return to hire a worker. Furthermore, the low worker's bargaining power implies that firms get large part of the match surplus, leading to more vacancy creation. This leads to a persistent response of vacancy creation. Due to the timing assumption of the matching process, on the impact of the shock, unemployment does not respond and falls in the following periods.

Next, we consider the response of unemployment and vacancies to a separation shock. On impact, unemployment jumps up and then declines in the following periods. An increase in unemployed workers increases the number of job seekers. As a result, firms have higher incentives to create more vacancies. Thus, on the impact of a positive shock on the separation rate, vacancies increases and then declines in the following period since the number of unemployed workers fall.

\section{Discussion}

In this section, we first assess the robustness of parameter estimates and the fit of the model to changes in the model specification and choice of observables. We then explore the role of wage rigidity.

\subsection{Robustness}

In the first robustness check, we change priors for the worker's bargaining power and the unemployment flow benefit since these parameters have been the subject of some discussion in the literature. We first tighten the prior on $\eta$ without changing the benchmark priors for other parameters. Specifically, we impose a Beta distribution with mean 0.5 and standard deviation of 0.15 . The posteriors means are very close to those in the benchmark case. The posterior mean of $\eta$ is 0.43 with a $90 \%$ coverage interval $[0.19,0.65]$ and the other posterior means are not substantially affected. We also experiment with decreasing the mean of the prior on the flow value of unemployment utility. We set $b$ at a prior mean of 0.4. Similar to the previous case, the posteriors means are not substantially affected.

In the second robustness check, we remove the separation shock and incorporate a persistent shock to match efficiency $m$ as the second disturbance in place of the separation rate. $^{12}$ Specifically, we assume that $\log m_{t}$ follows a first-order autoregressive process of the form:

$$
\log m_{t}=\left(1-\rho_{m}\right) \log m+\rho_{m} \log m_{t-1}+\varepsilon_{m, t},
$$

\footnotetext{
${ }^{12}$ The separation rate is now treated as a fixed parameter.
} 
where $0<\rho_{m}<1$ and $\varepsilon_{m, t} \sim N\left(0, \sigma_{m}^{2}\right)$. The mean of the matching process $m$ is a structural parameter to be estimated. Now the matching shock takes the role of a residual in the employment equation (2). The difference between matching shocks and separation shocks is the timing of their effects. While separation shocks affect current employment, matching shocks affect it with a one-period lag. We choose the priors as in the benchmark specification.

The results are reported in Tables 5 and 6 . The estimates are remarkably different from those in the benchmark case. The bargaining power $\eta$ becomes larger, while the unemployment benefit $b$ gets smaller. Furthermore, the vacancy posting elasticity $\phi$ becomes smaller and the estimate suggests that the vacancy cost function is is approximately linear. These results imply that matching shocks play an important role in explaining unemployment and vacancy dynamics. Without matching shocks, as in our benchmark model, the estimation algorithm needs compensate and requires a low bargaining power and a high replacement ratio as suggested in the literature. Since the worker's bargaining power falls in the model with matching shocks, the vacancy cost elasticity also declines. With matching shocks, the model matches the volatility in unemployment and vacancy remarkably well. However, the model implied volatility of output and wage is different from the data. The variance decomposition shows that matching shocks explain $20 \%$ of the volatility in unemployment and $5.9 \%$ in vacancies.

Based on the robustness exercises, we have the following findings. First, some parameter estimates of the model are fairly consistent across specifications. Specifically, the parameters associated with the matching function, $\alpha$ and $m$, the separation rate $s$, and the scale parameter in the vacancy cost function kappa do not show much variation. The other parameters, especially $\eta, b$, and $\phi$, show more variation. Basically, the model matches the second moments of unemployment and vacancies reasonably well. However, the model fails to match the volatility in output and wage. This implies that the search and matching model does not a good job to fit the data overall.

\subsection{The model fitness}

In the benchmark case, we use data on unemployment and vacancies to estimate our model. We find that the volatility of output and wage are higher than the data. This implies that the Shimer puzzle holds. This finding motivates us to consider the following hypothetical situation. Suppose the model now could successfully serve as the data-generating process for the output and the unemployment rate (i.e. the model could generate "enough" rela- 
Table 5: Robustness: parameter estimates

\begin{tabular}{llllllllllll}
\hline \hline \multirow{2}{*}{ Parameter } & \multirow{2}{*}{ Benchmark } & \multicolumn{2}{c}{ Matching shock } & \multicolumn{2}{c}{ observables: $y$ and $u$} & \multicolumn{2}{c}{ observables: $y$ and $w$} & \multicolumn{2}{c}{ Wage rigidity } \\
& Mean & Mean & $90 \%$ Interval & Mean & $90 \%$ Interval & Mean & $90 \%$ Interval & Mean & $90 \%$ Interval \\
\hline$\alpha$ & 0.599 & 0.571 & {$[0.514,0.635]$} & 0.501 & {$[0.254,0.707]$} & 0.270 & {$[0.140,0.416]$} & 0.603 & {$[0.562,0.644]$} \\
$m$ & 0.348 & 1.348 & {$[0.724,1.803]$} & 0.190 & {$[0.112,0.256]$} & 0.191 & {$[0.120,0.263]$} & 0.279 & {$[0.196,0.360]$} \\
$s$ & 0.011 & 0.012 & {$[0.009,0.015]$} & 0.013 & {$[0.010,0.015]$} & 0.010 & {$[0.007,0.013]$} & 0.012 & {$[0.010,0.015]$} \\
$\eta$ & 0.316 & 0.675 & {$[0.359,0.885]$} & 0.215 & {$[0.000,0.426]$} & 0.064 & {$[0.015,0.117]$} & 0.675 & {$[0.373,0.939]$} \\
$b$ & 0.855 & 0.331 & {$[0.068,0.606]$} & 0.595 & {$[0.251,0.964]$} & 0.744 & {$[0.493,0.942]$} & 0.654 & {$[0.382,0.940]$} \\
$\phi$ & 4.394 & 1.389 & {$[1.207,1.582]$} & 1.263 & {$[0.628,1.954]$} & 1.534 & {$[1.141,2.187]$} & 4.3153 & {$[3.035,5.439]$} \\
$\kappa$ & 0.419 & 0.316 & {$[0.164,0.479]$} & 0.409 & {$[0.272,0.554]$} & 0.478 & {$[0.371,0.598]$} & 0.449 & {$[0.296,0.598]$} \\
\hline
\end{tabular}

Table 6: Robstness: measure of fit

\begin{tabular}{lcccccc}
\hline \hline & Data & Benchmark & $\begin{array}{c}\text { Matching } \\
\text { shock }\end{array}$ & $\begin{array}{c}\text { Observables: } \\
y \text { and } u\end{array}$ & $\begin{array}{c}\text { Observables: } \\
y \text { and } w\end{array}$ & Wage rigidity \\
\hline$\sigma(u)$ & 0.061 & 0.078 & 0.064 & 0.067 & 0.170 & 0.050 \\
$\sigma(v)$ & 0.095 & 0.099 & 0.074 & 0.047 & 0.076 & 0.061 \\
$\sigma(w)$ & 0.010 & 0.058 & 0.106 & 0.005 & 0.014 & 0.016 \\
$\sigma(y)$ & 0.013 & 0.065 & 0.109 & 0.013 & 0.012 & 0.022 \\
$\rho(u, v)$ & -0.803 & -0.815 & -0.743 & 0.845 & 0.861 & -0.675 \\
\hline
\end{tabular}

tively volatility of unemployment to output), what are parameter values supporting this hypothesis? In addition, how well can the model explain the dynamics of variables that are not included in estimation, i.e., vacancies and wages?

The results are reported in the fourth column of Tables 5 and 6 . We find that some of the estimated parameters are closer to the prior means: the unemployment benefit $b$ and the vacancy posting elasticity $\phi$. On the other hand, comparing to the baseline case, bargaining power gets smaller and the value is 0.22 . Regarding to the volatilities, given the fact that the model could successfully accounts for the volatilities for the output and unemployment rate, the implied volatilities of vacancies and wages are smaller than the data. The serious issue is that the model fails to generate a negative relationship between unemployment and vacancies. This failure can be understood by looking at variance decompositions and correlation. In the estimated model, unemployment and vacancies are exclusively driven by separation shocks. ${ }^{13}$ Since correlations between unemployment and separation and between

\footnotetext{
${ }^{13}$ Variance decomposition results show that productivity shocks explain 0.1 percent of the volatility in unemployment, $1.1 \%$ in the vacancy rate, 80.4 percent in wages, and 97.5 percent in outputs.
} 
vacancies and separation are positive, the model generates the positive relationship between unemployment and vacancies, although unemployment is counter-cyclical and vacancies are pro-cyclical.

We also experiment with using the observations on output and wage in place of unemployment and vacancies. The estimates are different from the benchmark case. The worker's bargaining power is close to zero. The posterior means of the unemployment benefit and the vacancy cost elasticity get smaller values. The model fails to account for the volatility of unemployment and vacancies as we expected. Based on the variance decomposition result, while wages are mainly driven by separation shocks, outputs are driven by productivity shocks. ${ }^{14}$ The model again fails to generate a negative relationship between unemployment and vacancies.

\subsection{The role of wage rigidity}

A number of papers argue that an incorporation of wage rigidity improves the performance of a search and matching model to match the cyclical behavior of unemployment and vacancies (Hall, 2005; Shimer, 2005). We now assess whether an incorporation of wage rigidity improves the ability of our model to match the business cycle facts in the data.

Following Hall (2005) and Krause and Lubik (2007), we incorporate wage rigidity into our model in the form of a backward looking wage norm. Hall (2005) argues that a wage norm may arise from social convention that constrains wage adjustment. Without getting into the details of the wage norm, we assume that the actual wage is the weight average of a notional wage $w^{*}$ and a wage norm $w^{n}$ :

$$
w_{t}=\gamma w_{t}^{n}+(1-\gamma) w^{*}
$$

where $\gamma \in[0,1]$. We assume that the notional wage is equal to the bargaining solution of our benchmark model and the wage norm is the wage in the steady-state of the benchmark model. We assign the parameter $\gamma$ a Beta distribution with support on the unit interval. We set gamma at a mean of 0.5 with a wide coverage region. For other parameters, we use the prior specification in the benchmark case.

The results are reported in Tables 5 and 6 . The posterior means are close to those in the benchmark model. Regarding the volatility in labor market variables, the model with wage rigidity does a good job and is successful in matching the data. The posterior mean of $\gamma$ is 0.34 with a $90 \%$ coverage interval $[0.10,0.61]$. The relative standard deviations of

\footnotetext{
${ }^{14}$ Productivity shocks explain 0.2 percent of the volatility in unemployment, $0.4 \%$ in the vacancy rate, 5.2 percent in wages, and 99 percent in outputs.
} 
unemployment and vacancies to output are 2.27 and 2.77 , respectively. They explain $50 \%$ and $39 \%$ of the observed volatility, respectively. Regarding the correlation between $u$ and $v$, although the model with wage rigidity generates empirically consistent sign of it, the magnitude (in absolute value) becomes smaller than that in the benchmark case.

These results suggest that a sluggish wage determination mechanism improves the ability of a search and matching model to explain the volatility in unemployment, vacancies, and wage. However, the model with wage rigidity still fails to match the volatility in output.

\section{Conclusion}

This paper study how well a search and matching model describes aggregate Japanese labor market dynamics in a full information setting. We develop a simple search and matching model with productivity and separation shocks and use it as a data-generating process for our empirical analysis. We estimate the model by using Bayesian methods for data on unemployment and vacancies. The structural estimation of the full model allows us to study the ability of the model as description of labor market dynamics.

The results show that the model fits the data on unemployment and vacancies remarkably well. The model replicates the high volatility of unemployment and vacancies and a negative relationship between them. Furthermore, the model is successful in replicating the dynamic relationship between unemployment and vacancies. In order to match the data, the model estimates requires a high replacement ratio and a low worker's bargaining power. Thus, the estimation result pushes the parameter towards values that Hagedorn and Manovskii (2008) suggest in their calibration. However, the model fails to capture the volatility of wage and output. Thus, the model does not a good job to fit the data overall.

We also consider a sluggish wage determination mechanism and assess the viability of the model as description of labor market dynamics. The model with wage rigidity matches the volatility in unemployment, vacancies, and wage well. However, the model still fails to match the volatility in output.

A number of important issues remain for future research. First, using more data in the empirical analysis is important. In order to avoid a stochastic singularity problem, an empirical model needs at least as many sources of uncertainty as a number of observables. Thus, including more data series requires an incorporation of additional sources of variation into the model. Also, considering a medium scale macroeconomic model with labor market frictions and a monetary sector, and studying the effect of monetary policy shocks to the labor market would be interesting. 


\section{References}

[1] An, S., Schorfheide, F., 2007. Bayesian Analysis of DSGE Models. Econometric Reviews, 26(2-4), 113-172.

[2] Esteban-Pretel, J., Nakajima, R., Tanaka, R., 2010. Japan's Labor Market Cyclicality and the Volatility Puzzle. Graduate Institute for Policy Studies, Mimeo.

[3] Hagedorn, M., Manovskii, I., 2008. The cyclical behavior of equilibrium unemployment and vacancies revisited. American Economic Review 98 (4), 1692-1706.

[4] Hall, R.E., 2005. Employment Fluctuations with Equilibrium Wage Stickiness. American Economic Review 95(1), 50-65.

[5] Hornstein, A., Krusell, P., Violante, G., 2005. Unemployment and Vacancy Fluctuations in the Matching Model: Inspecting the Mechanism. Economic Quarterly (Federal Reserve Bank of Richmond), Vol. 91(3), 19-51.

[6] Kano, S., Ohta, M., 2002. An empirical matching function with regime switching: the Japanese case. Discussion Paper No. 967, Institute of Policy and Planning Sciences, University of Tsukuba, Tsukuba, Japan.

[7] Krause, M. U., Lubik, T. A., 2007. The irrelevance of real wage rigidity in the New Keynesian model with search frictions. Journal of Monetary Economics 54(3), 706727.

[8] Lin, C.-Y., Miyamoto, H., 2012. Gross Worker Flows and Unemployment Dynamics in Japan. Journal of The Japanese and International Economies 26(1), 44-61.

[9] Lubik, T. A., 2009. Estimating a Search and Matching Model of Aggregate Labor Market. Economic Quarterly 95(2), 101-120.

[10] Lubik, T. A., 2011. Aggregate labor market dynamics in Hong Kong. Pacific Economic Review (forthcoming).

[11] Martin, J.P., 1998. What works among active labour market policies: evidence from OECD countries' experiences. OECD Labour Market and Social Policy-Occasional Papers No.35.

[12] Miyamoto, H., 2011. Cyclical behavior of unemployment and job vacancies in Japan. Japan and the World Economy. 23, 214-225. 
[13] Mortensen, D.T., Nagypál, E., 2007. More on unemployment and vacancy fluctuations. Review of Economic Dynamics 10(3), 327-347.

[14] Petrongolo, B., Pissarides, C., 2001. Looking Into the Black Box: A Survey of the Matching Function. Journal of Economic Literature, 39, 390-431.

[15] Pissarides, C.A., 2000. Equilibrium Unemployment Theory, 2nd ed. MIT Press, Cambridge, MA.

[16] Rotemberg, J, J., 2008. CyclicalWages in a Search-and-Bargaining Model with Large Firms. In NBER International Seminar on Macroeconomics 2006. Chicago: University of Chicago Press, 65-114.

[17] Shimer, R., 2005. The cyclical behavior of unemployment and vacancies: evidence and theory. American Economic Review 95, 25-49.

[18] Tawara, N., 2011. The ins and outs of cyclical unemployment in Japan. Kanto-gakuen University, Mimeo. 


\section{Appendix}

The model is log-linearized around the steady-state. The variable with superscript "star" represents its steady-state value and the variable with "hat" represent the log-deviation of a variable from its steady-state. Thus, $\hat{x}_{t}=\log x_{t}-\log x^{*}$.

Log-Linearlized Equilibrium Conditions are

$$
\begin{aligned}
w^{*} \hat{w}_{t}= & \eta\left[A^{*} \hat{A}_{t}+\kappa \theta^{*} v^{* \phi-1}\left\langle\hat{\theta}_{t}+(\phi-1) \hat{v}_{t}\right\rangle\right], \\
\hat{\theta}_{t}= & \hat{v}_{t}-\hat{u}_{t}, \\
\hat{n}_{t}= & -s^{*} \hat{s}_{t}\left[1+\frac{v^{*} q^{*}}{n^{*}}\right]+\left(1-s^{*}\right)\left[\hat{n}_{t-1}+\frac{v^{*} q^{*}}{n^{*}}\left(\hat{v}_{t-1}+\hat{q}_{t-1}\right)\right], \\
\hat{q}_{t}= & -\alpha \hat{\theta}_{t}, \\
0= & n^{*} \hat{n}_{t}+u^{*} \hat{u}_{t}, \\
\hat{y}_{t}= & \hat{A}_{t}+\hat{n}_{t}, \\
\frac{\kappa v^{* \phi-1}}{q^{*}}\left[(\phi-1) \hat{v}_{t}-\hat{q}_{t}\right]= & \beta\left(1-s^{*}\right) \mathbb{E}_{t}\left[A^{*} \hat{A}_{t+1}-w^{*} \hat{w}_{t+1}+\frac{\kappa v^{* \phi-1}}{q^{*}}\left\langle(\phi-1) \hat{v}_{t+1}-\hat{q}_{t+1}\right\rangle\right] \\
& -s^{*} \beta \mathbb{E}_{t}\left[A^{*}-w^{*}+\frac{\kappa v^{* \phi-1}}{q^{*}}\right] \hat{s}_{t+1} .
\end{aligned}
$$




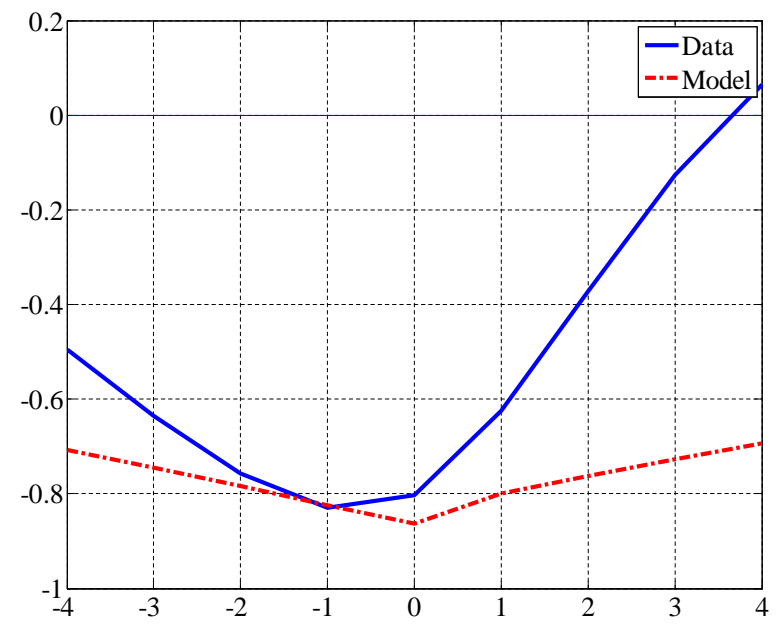

Figure 1: Correlation between $u_{t}$ and $v_{t+i}$
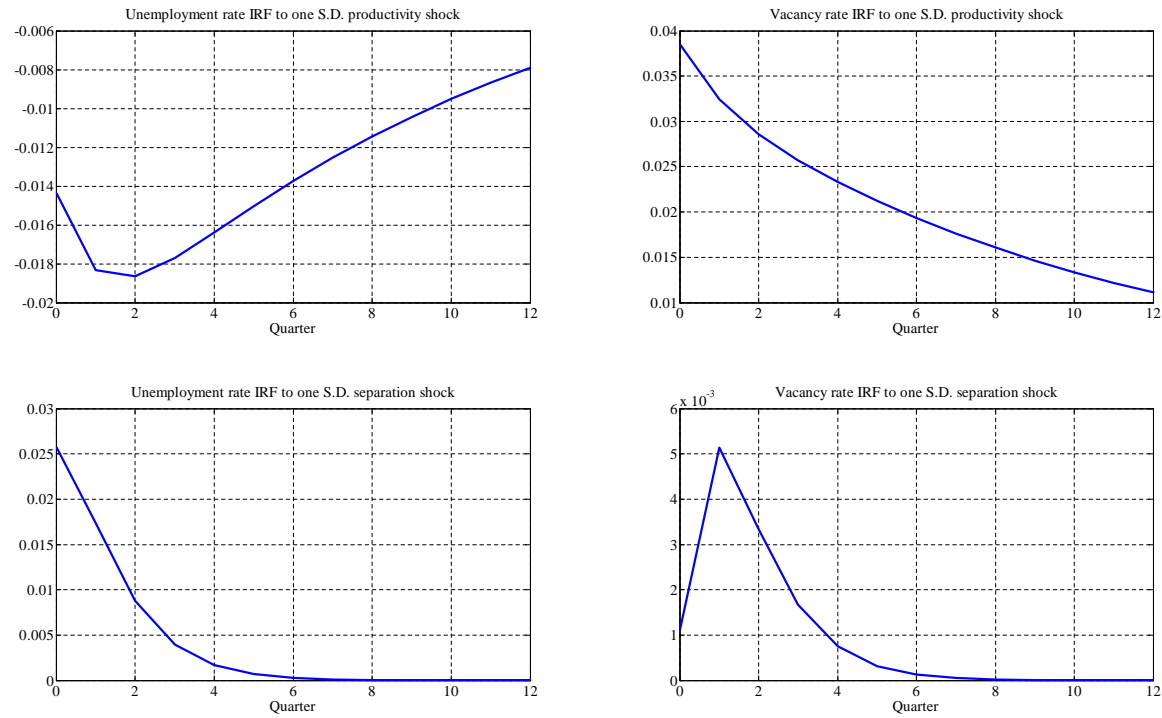

Figure 2: Impulse responses to productivity and separation shocks 